\title{
Numerical simulation analysis of surrounding rock displacement of double shield tunnel
}

\author{
Deshen Zhao ${ }^{1, a}$, Yunping Wang $1, \mathrm{~b}^{2, \mathrm{~b}}$ and Menglin $\mathrm{XU}^{3, \mathrm{C}}$ \\ ${ }^{1}$ Key Laboratory of Liaoning Province for Prediction and Control on Complicated Structure System, \\ Dalian University, Dalian 116622, China \\ a zhaodeshen@dlu.edu.cn , bWangYunPingJG211@163.com, ${ }^{\mathrm{c}} 2826848532 @ q q . c o m$
}

Keywords: Numerical simulation; Fluid-solid coupling; Surrounding rock displacement

Abstract. Tunnel engineering is an important part of the development and utilization of underground space especially in the city. To alle viate traffic pressure, improve the efficiency of traffic greatly. This paper will use the numerical simulation software FLAC3D, to simulate the Sub way tunnel excavation. Analysis of whether considering fluid solid coupling under two conditions of surrounding rock displacement distribution and the relationship between the settlement and the position of the nodes. The results show that, the tunnel of surrounding rock vault settlement is closely re lated to the node location, The closer from tunnel excavation area, the final settlement amount is large.

\section{Introduction}

With the rapid growth of population, The shortage of resources lead to the survival of the human resources overwhelmed, The development and utilization of underground space has become the focus of the world to explore and research. In this paper, using software FLAC3D to simulate the construction site to study the distribution of displacement field of surrounding rock ${ }^{[1-3]}$. Using finite difference program FLAC-3D and comparison of measured data, verifying of the finite difference numerical simulation method of the reliability and the calculation results ${ }^{[4-6]}$.

\section{Establishment of calculation model and calculation parameters}

Rock density is $1800 \mathrm{~kg} / \mathrm{m}^{3}$, volume modulus is $1.47 \mathrm{e} 8 \mathrm{~Pa}$,cohesion is $5.0 \mathrm{e} 4 \mathrm{~Pa}$, the tensile strength of $1.0 \mathrm{e} 4 \mathrm{~Pa}$, the shear modulus of elasticity is $5.6 \mathrm{e} 7 \mathrm{~Pa}$, the friction angle is 20 degrees. Tunnel lining structure using C30 concrete, the density is $2500 \mathrm{~kg} / \mathrm{m}^{3}$, the bulk modulus is $16.7 \mathrm{Mpa}$, the modulus of shear is $12.5 \mathrm{Mpa}$, osmotic coefficient is $3.0 \times 10-4 \mathrm{~cm} / \mathrm{s}$, porosity is $0.42 \%$. Tunnel diameter is $6.0 \mathrm{~m}$, lining thickness is $0.3 \mathrm{~m}$, inside diameter is $5.4 \mathrm{~m}$, the depth is $10 \mathrm{~m}$. the model size is $72 \mathrm{~m} \times 36 \mathrm{~m} \times 36 \mathrm{~m}(\mathrm{X} \times \mathrm{Y} \times \mathrm{Z})$. Each longitudinal excavation simulation calculation with 5 segment as a group (each ring width is $1.2 \mathrm{~m}$ ), each time the tunnel length of longitudinal construction is $6.0 \mathrm{~m}$, installation segment lining after each excavation completed,exerting the supporting pressure, the right tunnel excavation after the completion of all the left tunnel excavation. Underground water from the surface of $0.6-1.2 \mathrm{~m}$, the calculation of groundwater level is taken as the surface, the left and right boundary are impervious to water. The calculation model is divided into 39456units, 41404 nodes. 3D model of double line shield tunnel shown in figure 1 and figure2.

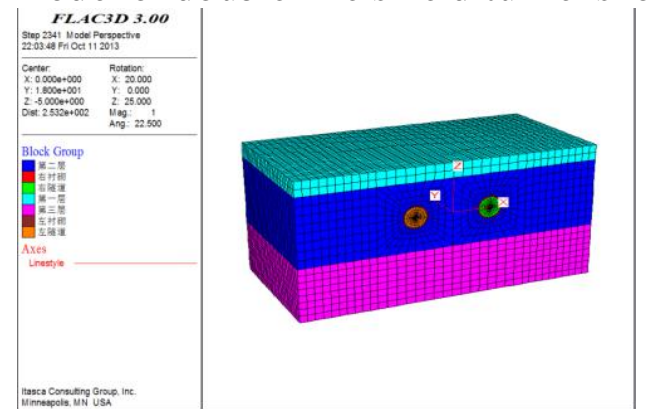

Fig.1 Dimensional model of double shield tunnel

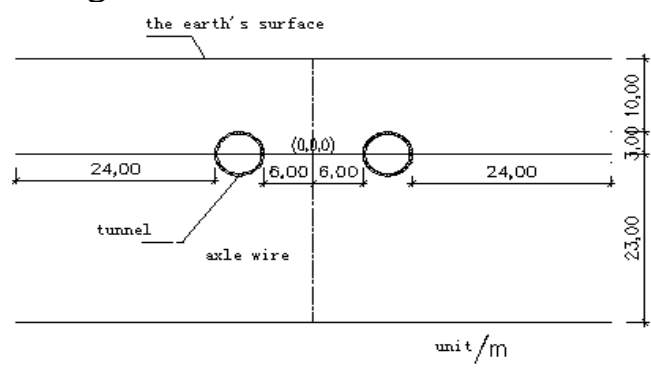

Fig.2 $\mathrm{Y}=0 \mathrm{~m}$ section layout of metro shield tunnel 


\section{The horizontal displacement field of surrounding rock}

Based on the above numerical model we will to study surrounding rock displacement field distribution., the analysis of two kinds working conditions of whether to consider the fluid solid coupling, as follows:

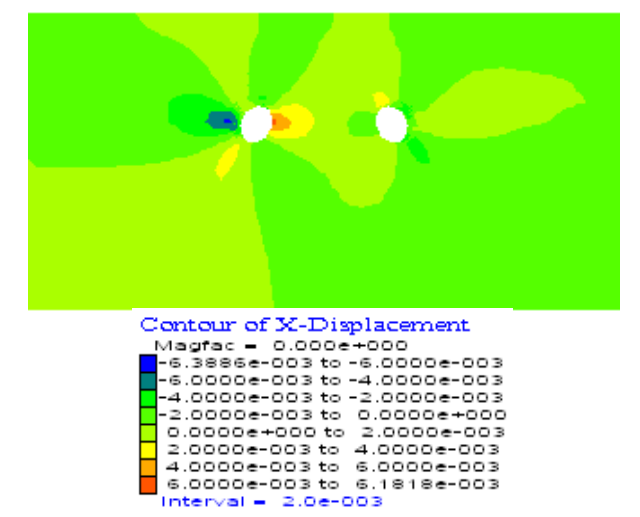

(a) Not considering fluid-structure coupling

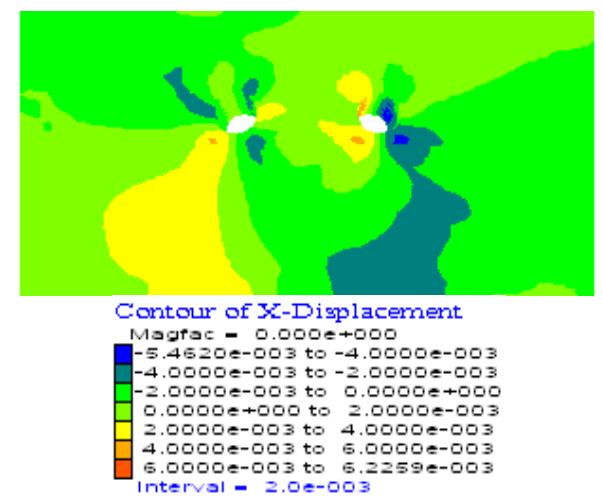

(b) Considering fluid-structure coupling

Fig.3 Surrounding rock horizontal displacement nephogram after double tunnel excavation

Figure 2 (a), (b) respectively the Surround ing rock horizontal displacement nephogram under the conditions of whether to consider the fluid solid coupling. Among them, rihtht is positive, left is negative, the unit is $\mathrm{mm}$. By figure (a) shows that, without considering the condition of fluid solid coupling effect the maximum displacement distribution concentrated in near the excavation area, the maximum horizontal displacement value is $6.39 \mathrm{~mm}$, by the side wall in the tunnel to both sides of the expansion; By figure (a) shows that, considering the effect of fluid solid coupling the maximum horizontal displacement value is $6.23 \mathrm{~mm}$, appeared in the both sides of the tunnel, the displacement of surrounding rock is the convergence to the side after tunnel excavation. It can be seen from the above, whether or not to consider the fluid solid coupling effect, the horizontal displacement are relatively small, mainly due to the tunnel surrounding rock radial convergence, the seepage make little effect to the field of surrounding rock displacement.

\section{The vertical displace ment distribution of surrounding rock}

In the numerical simulation, monitoring the vertical displacement of tunnel, select vault node of the left and right hole, the monitoring node number as shown in the table 1.

Tab.1 Surrounding rock displacement monitoring node location of tunnel and soft

\begin{tabular}{ccc}
\hline $\begin{array}{l}\text { Monitoring } \\
\text { node umber }\end{array}$ & $\begin{array}{l}\text { Location } \\
/ \mathrm{m}\end{array}$ & Node number \\
\hline 1 & $-9,18,3$ & 18 \\
2 & $-8,18,6$ & 22 \\
3 & $9,18,3$ & 32 \\
4 & $8,18,6$ & 34 \\
5 & $-9,18,-3$ & 37 \\
6 & $9,18,-3$ & 41 \\
7 & $-8,18,-6$ & 43 \\
8 & $8,18,-6$ & 44 \\
\hline
\end{tabular}

Leading-out the monitor node displacement data of numerical simulation by using the Hist command, deal with the information by Data processing software of Excel, Setting every 100 steps to monitor 
the data, considering fluid-structure coupling, obtained the vertical settlement of vault with two conditions of whether considering the effect of fluid-structure coupling.

Fig.4 is the double tunnel arch monitoring node settlement graph, of which not considering fluid-structure coupling. It can be seen from the figure, surrounding rock deformation is obvious in the range of tunnel excavation, the influence of vertical displacement of surrounding rock has reached the surface, the vertical displacement of the vault surrounding rock is negative, indicating that the tunnel vault settlement, and produces a downward displacement of surrounding rock in a certain region above the vault, leading to the subsidence of ground surface above the tunnel, the maximum settlement of the vault has reached $11.8 \mathrm{~mm}$;

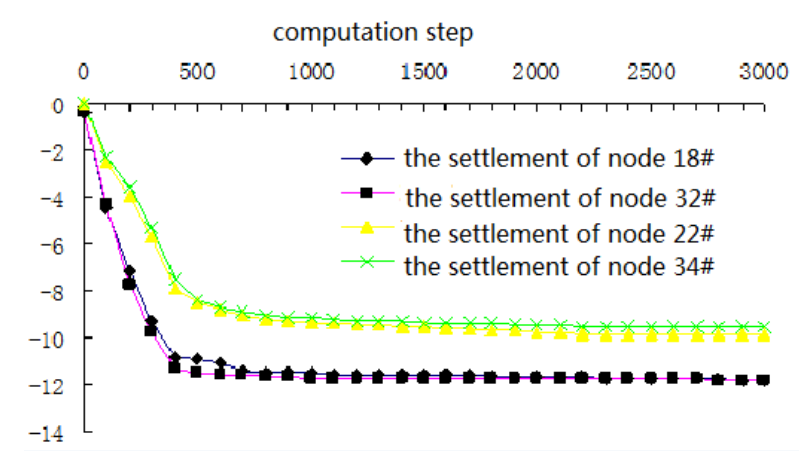

Fig.4 Double tunnel arch monitoring node settlement graph (Not considering fluid-structure coupling)

Fig.5 is the Double tunnel arch monitoring node settlement graph ,of which considering fluid-structure coupling. It can be seen from the figure, under the condition of considering the fluid solid coupling effect, the vertical deformation of the monitoring nodes is gradually increases, along with the increase of calculation time step, the final calculated settlement of the monitoring nodes(18\# and $32 \#$ node)of the left and right tunnel is about $21.4 \mathrm{~mm}$, the final settlement of monitoring nodes (32\# node)of the tunnel right hole are slightly less than $21.4 \mathrm{~mm}$, surrounding rock disturbance caused by the excavation of left tunnel, so that the final settlement of the monitoring nodes is about $21.4 \mathrm{~mm}$;

when left and right tunnel excavation of about $5 \mathrm{~m}$, the value of arch crown settlement can reach the maximum, then it tends to be stable; The amount of settlement is associated with the node position, the nearer to the tunnel excavation zone, the larger the final settlement. Farther away from the tunnel excavation zone, the smaller the final settlement of the other nodes (34\#, 22\# node) .

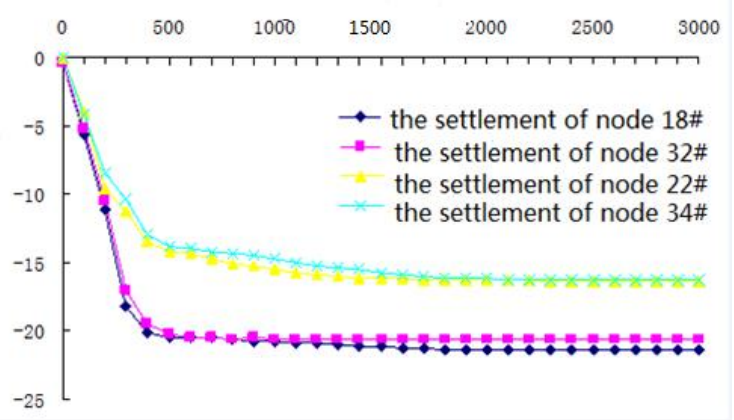

Fig.5 Double tunnel arch monitoring node settlement graph (considering fluid-structure coupling) 
Under the condition of considering the fluid solid coupling effect, final settlement range and settlement of vault nodes of monitoring were significantly increased compared with the condition of not considering the fluid solid coupling effect, the consolidation settlement caused by the decrease of pore water pressure in the funnel - shaped zone ; the change law of settlement of the vault monitoring nodes are consistent with the not considering fluid-structure coupling effect.

\section{Summary}

(1)Under the condition of considering fluid-structure coupling and not considering fluid-structure coupling, the amount of settlement is associated with the node position, the nearer to the tunnel excavation zone, the larger the final settlement. The final settlement amo unt of the monitoring nodes of right tunnel are slightly smaller than the left one, because of surrounding rock disturbance caused by the first excavation of left tunnel.

(2)Because of the tunnel excavation, the pressure of the pore water in the zone of funnel is reduced, so that consolidation settlement. The final settlement range and settlement of vault nodes of monitoring were significantly increased compared with the condition of not considering the fluid solid coupling effect.

\section{Acknowledgements}

The author would like to thank the financial support by the National Natural Science Foundation of China (Grant No. 51274051).ZHAO Deshen(1957-) male,the elm city of Jilin Province,university profes sor, Doctor.

\section{References}

[1] Qian Qi-hu. greeting the high tide of beginning of urban underground space in china[J].Chinese Journal of Geotechnical Engineerin, 1998,20(1):112-113.

[2] Liu bao-jun. Some aspects for utilization of ground surface and under ground space in cities[J].ChineseJournal of Rock Mechanics and Engineering, 1999,18(1):109-111.

[3] Wang Dong Cheng Yu-wei. Research on Urban Underground Space Development Strategies in Northern Area of Jiangsu Province[J]. Jiangsu building, 2012,01:8-10+14

[4] Gao Chen-hua. Research on cases of combination of civil defense projects and underground space development[J].Shanxi Architecture,2014,35:36-38

[5] Pan Jie, Han Wen-xing, Zheng Yong-lai. Analysis on the Settlements of Metro Tunnels in Soft Soil[J]. Chinese Journal of Underground Space and Engineering,2005,01:67-74.

[6] Louis C. Rock Hydraulics in Rock Mechanics [M]. New York, Wiley, 1974. 